\title{
The Impact of New Product Introduction on Inter-tier Price Competition: An Abstract
}

\author{
K. Sivakumar
}

\begin{abstract}
Extensive research exists in two important research domains: (1) short-term price competition between high-tier brands and low-tier brands and (2) how new brand introductions influence customer choice among existing alternatives. The current research integrates these two research streams. Specifically, the research examines the impact of new brand introductions on the nature of shortterm price competition between high-tier and low-tier brands. Using a conceptual framework based on prospect theory, the research derives a number of research propositions that predict how the nature of price competition between a high-tier brand and a low-tier brand is influenced by reference price contexts as well as the attributes of the newly introduced brand. Implications for understanding inter-brand competition and new brand introduction, guidelines for managerial practice, and future research directions are delineated.
\end{abstract}

References Available Upon Request

K. Sivakumar $(\bowtie)$

Lehigh University, Bethlehem, PA, USA

e-mail: k.sivakumar@lehigh.edu 